\title{
Autonomous coop cooling system using renewable energy and water recycling
}

\author{
Shamsul Kamal Ahmad Khalid, Nurul Shafiqah Che Dan, Noor Azah Samsudin, \\ Muhammad Syariff Aripin, Nor Amirul Amri Nordin \\ Faculty of Computer Science and Information Technology, Universiti Tun Hussein Onn Malaysia, Malaysia
}

\begin{tabular}{l}
\hline \hline Article Info \\
\hline Article history: \\
Received Oct 8, 2018 \\
Revised Dec 7, 2018 \\
Accepted Dec 20, 2018 \\
\hline
\end{tabular}

Keywords:

Autonomous system

Chicken coop

Internet of Things (IOT)

Temperature

\begin{abstract}
Extreme temperature in a chicken coop can significantly affect the growth and productivity of poultry. Therefore, the temperature inside the chicken coop need to be controlled to protect it from extreme temperatures. Most of the technology use electrical energy supplied to an evaporative cooling system to control the temperature of a coop. This paper presents an autonomous chicken coop cooling system using renewable energy and water recycling (REMACT). In this study, a monitoring system with necessary hardware, control application, powered with solar power source and water recycling, has been developed. The proposed cooling system consists of hardware part such as an Internet of Things (IOT) controller platform, temperature sensor, solar panel, water pump, water storage, water drain and pipe. When the temperature sensor detects extreme temperature more than $28^{\circ} \mathrm{C}$ in a chicken coop, the water in storage tank will flow throughout the pipe and pass into water pump before it irrigates the chicken coop roof. When the temperature is below $22^{\circ} \mathrm{C}$, the bulb will light up to transfer heat to the chicken coop and cause the temperature drop back to a healthy range. The water drain that is attached to the roof will collect the water and return the water back to the water storage again. The software components required by the project are Arduino IDE, Thinger.io, and Android Studio Framework. Several experiments have been conducted with hot and cold scenarios. The system was able to stabilise the temperature back to a healthy range. A usability testing result demonstrates $80 \%$ satisfactory rate. The findings from the experiments show that IoT, renewable energy and water recycling have the potential for temperature control of a chicken coop.
\end{abstract}

Copyright $@ 2019$ Institute of Advanced Engineering and Science. All rights reserved.

\section{Corresponding Author:}

Shamsul Kamal Ahmad Khalid,

Faculty of Computer Science and Information Technology,

Universiti Tun Hussein Onn Malaysia,

86400 Batu Pahat, Johor, Malaysia.

Email: shamsulk@uthm.edu.my, azah@uthm.edu.my

\section{INTRODUCTION}

To support healthy living, chicken coops must be designed to provide healthy environment for the chicken. Environmental extremes such as heat and cold stress, excessive or inadequate ventilation and poor air quality can contribute to shorter life of the chicken. Furthermore, chickens require adequate space, sufficient feeding to meet their nutritional requirements, and last but not least, an adequate supply of good air quality. In today's world, it is quite normal for chicken breeders to compensate the undesirable climate conditions by modifying the chicken house or adding control systems to ensure the welfare and environmental needs of the chicken are met [1].

Of these factors, a coop's temperature is one of its most important area. Daverow shows that a chicken's body operates most efficiently at an effective air temperature between $21^{\circ} \mathrm{C}$ to $29^{\circ} \mathrm{C}$, which is the 
identical temperature range for good health and productivity [2]. The warmest temperature that defines this comfort zone is the critical high temperature, above which chickens suffer heat stress. The lowest the temperature is the critical low, below which chickens suffer cold stress. The degree of heat stress a chicken suffers depends on how fast the temperature changes and how long the extreme temperature lasts. So the exact temperature range that defines the comfort zone depends, in part on how well acclimated the chickens are to temperature extremes. Chicken performance in controlled-environment sheds is generally superior to that in naturally ventilated houses, as the conditions can be maintained in the chicken's thermal comfort zone [3].

Improvements to poultry housing systems in developing countries have focused on providing an environment that satisfies the chicken's thermal requirements with low cost maintenance concern to reduce selling price of the chicken. Several work have been done to improve the control of temperature in a coop. In this regard, three representative types of existing systems have been selected as reference materials. The selected systems are Cooling Poultry Basic Principles of Humidity and Temperature Control [4], Housing and Managements of Poultry Breeding [5], and Poultry Housing in Arab World: Applying Principles of Thermal Exchange to Improve Performance (A case study of Morocco) [6]. The primary techniques revolve around providing evaporative cooling (fan systems) and also "cold" roof (via some insulation). In all cases, electrical energy were used as the main power source. Most of the technology used today for controlling chicken coop temperature is through Evaporative Cooling (EC) system such as electrical fans [5]. Chicken breeders need to go to their farm to manually control electrical fans when extreme temperature occurs.

Alternatively, recent technologies can be utilized to improve the cooling of coop autonomously with low cost energy and lower maintenance cost. Some of these technologies include Internet of Things (IoT) Platform, Temperature Sensor, Solar Charger Controller and Panel, and Cloud-based Database.

a) Internet of Things (IoT) Platform

Internet of Things (IOT) is a global platform for information seeking communities, enabling advanced services by connecting things either physical or virtual based on information and communication between existing and growing technology operators [7]. IOT can also be seen as a vision with the implications of technology and society with a wider perspective. IOT is usually referred as interconnected by everyday objects that often come with intelligence that always exists. Internet space is enhance by integrating each object into interacting through an embedded system that leads to a highly distributed array of communication devices between humans and other devices. IOT has been applied in many problem domains such as in factories [8], agriculture and farming [9], hospital [10] and waste management [11].

A non intelligent system can be made part of the IOT by adding an IOT controller to it. An example of this is known as NodeMCU, which is an open source IoT platform [12]. According to its manual, it includes firmware which runs on the ESP8266 Wi-Fi SoC from Espressif Systems, and hardware which is based on the ESP-12 module. The term "NodeMCU" by default refers to the firmware rather than the development kits. It is based on the eLua project, and built on the Espressif Non-OS SDK for ESP8266. [12] b) Temperature Sensor

A digital humidity and temperature sensor senses the temperature and humidity of the surrounding and gives a calibrated digital signal output. The sensor includes a resistive humidity measurement component along with an NTC temperature measurement component [13]. According to its manual, it is connected to an 8-bit microcontroller for high performance, which offers excellent quality, fast response and antiinterference ability. It has a low power operating range $(3 \mathrm{~V}-5 \mathrm{~V})$. The component is a 3-pin single row package and the major feature of this sensor is that the data for both temperature and humidity is available on a single data pin of the sensor.

c) Solar Charge Controller 12V (10 A)

A solar charge controller may provide best output in power delivery from solar panel to $12 \mathrm{v}$ or $24 \mathrm{v}$ battery whether charging a single or twin batteries, as mentioned in [14]. These PV Logic Pulse Width Modulation (PWM) controllers deliver sizeable benefits over standard charge controllers by achieving a constant battery voltage and thereby producing a higher charge efficiency, rapid recharging and a longer life expectancy for any battery. Dual battery charging function is ideal if twin batteries are used in a caravan or boat or to charge the leisure and vehicle battery in an RV. The dual charge function only occurs when a second battery is connected. In this configuration the controller will still focus its power delivery on the battery connected to the No 1 terminals until that battery is $70 \%$ fully charged. Once this is reached power will be delivered to both batteries equally until both are $100 \%$ charged.

d) Solar Panel

Solar panels, also known as modules, contain photovoltaic cells made from silicon that transform incoming sunlight into electricity rather than heat. Solar photovoltaic cells consist of a positive and a negative film of silicon placed under a thin slice of glass. As the photons of the sunlight beat down upon 
these cells, they knock the electrons off the silicon. The negatively charged free electrons are preferentially attracted to one side of the silicon cell, which creates an electric voltage that can be collected and channelled. This current is gathered by wiring the individual solar panels together in series to form a solar photovoltaic array.

e) Thinger.io

Thinger.io is the platform as a service or Platform as a Service (PaaS) designed for the Internet of Things (IOT) project. It allows internet-enabled devices to connect to the server and store data from the device, which then can be used in other applications via the Thinger.io API [15]. Applications can be created and are not limited to one platform. API that enables the creation of web based mobile-based applications. Through this platform, data can be stored in the cloud-based database called Firebase.

With the availability of these technologies, an autonomous chicken coop cooling system using solar energy and water recycling is proposed. It is a coop cooling system based on extending the idea of cooling the roof using water recycling and using renewable energy such as solar power. It also provides heating lamp to increase the temperature of the coop in the case of unhealthy cold weather. The system will autonomously activate either the water recycling or the lamp to maintain healthy temperature of the coop. It does not require manual control.

\section{RESEARCH METHOD}

Figure 1 shows the implementation framework of the proposed coop. The solar panel captures sunlight or radiation and convert it to electricity. The electricity will be stored into a rechargeable lead acid battery, $12 \mathrm{~V}$. Solar charged controller controls the flow of voltage and current. So that the battery can be used for a longer time and at the same time protect overall system from surge and sag. The battery provides electrical energy to the Arduino processor, water pump and led lamps. When the surrounding temperature is below $22^{\circ} \mathrm{C}$, the led (lamp) will turn on. For the temperature in the range of $22^{\circ} \mathrm{C}$ to $28^{\circ} \mathrm{C}$, both led lamps and water pump will not run because it is in the optimum temperature range for ideal growth and productivity of chickens. For the temperature beyond $28^{\circ} \mathrm{C}$, water pump will be activated to pump the water from the water storage and irrigate the top roof to maintain optimum temperature from exceeding the optimum range. The led lamps are sufficient for the prototype. In real life, the lamp can be replaced with standard heater elements.

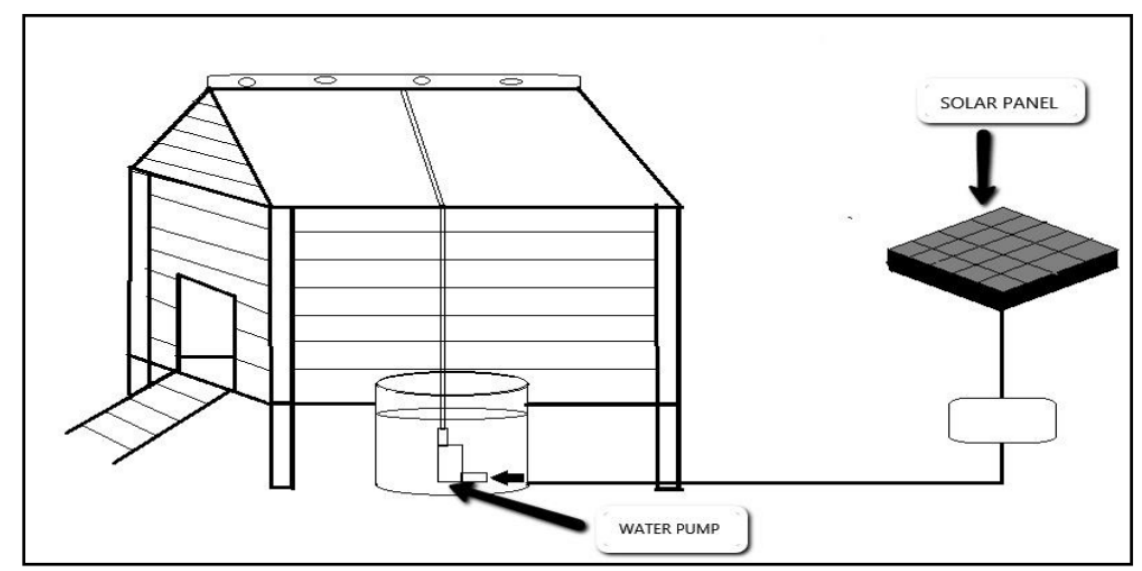

Figure 1. The implementation framework of REMACT

Figure 2 shows the sequence diagram for recording the current temperature reading to be displayed at the REMACT Application and also send it to the Firebase database server for analysis purposes. Figure 3 shows the REMACT Architecture. To facilitate module development, the architecture has been devided into 3-tier architecture, namely Presentation, Application and Data tiers. The user will access the Android Application which represents the Presentation Tier. The Application received current temperature readings from the sensor via the REMACT Hardware System which is made up of Android Middleware, IoT Controller ESP8266 and DHT11 Temperature Sensor. The Android application also able to retrieve previous temperature readings from the Firebase which represent the Data tier. The Controller is responsible to send temperature recordings to be stored in the Firebase.

Autonomous coop cooling system using renewable energy and water... (Shamsul Kamal Ahmad Khalid) 


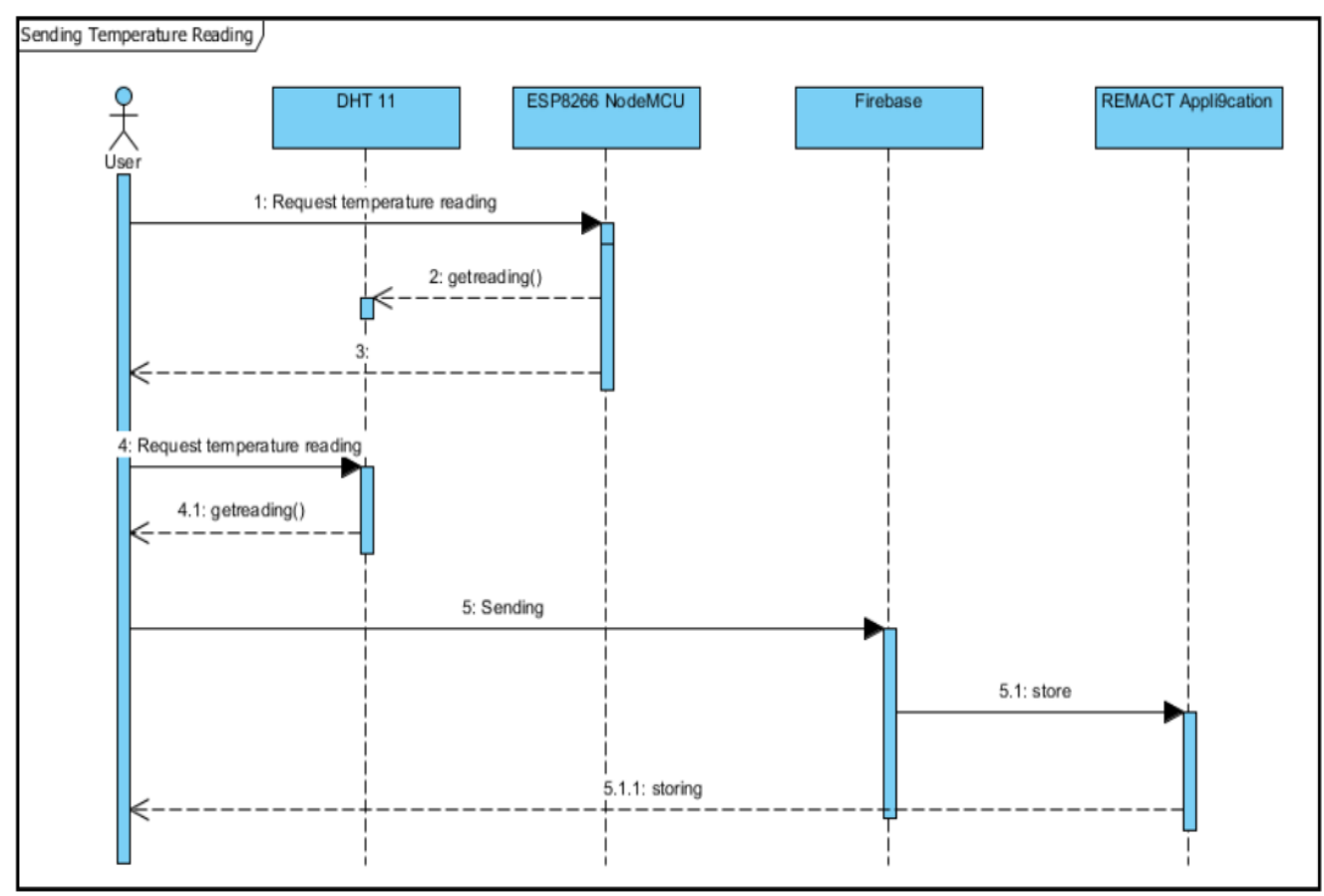

Figure 2. Sequence diagram for temperature sending to the application and firebase

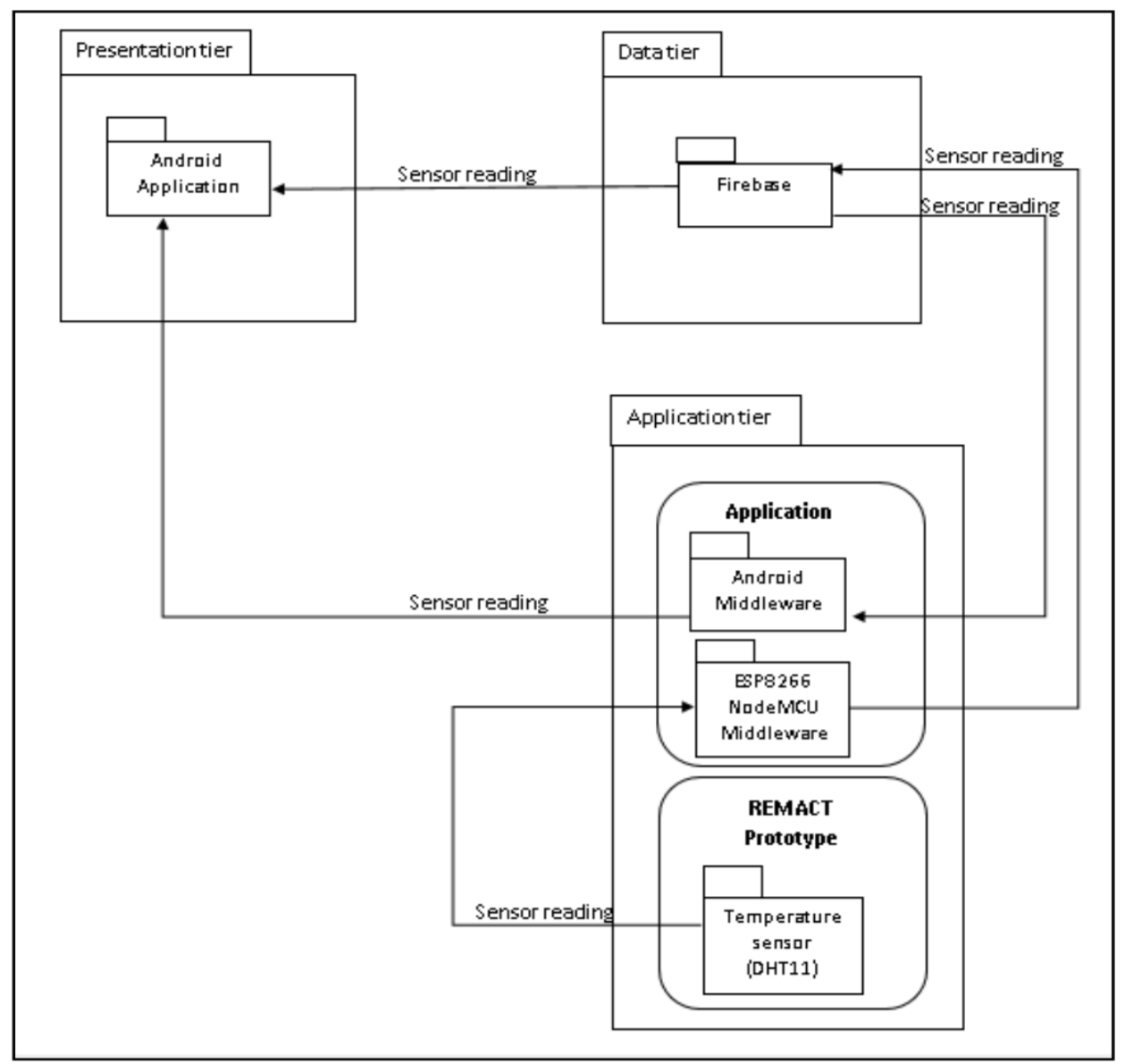

Figure 3. The REMACT architecture 
The detail of the Application Tier is given in Figure 4. In view of normal IPO (Input-ProcessOutput) development paradigm, the temperature sensor provides the Input, the ESP8266 Module and the Firebase Cloud Database provides the process and finally, the Android Application itself provide the Output to the users. The REMACT prototype is shown in Figure 5.

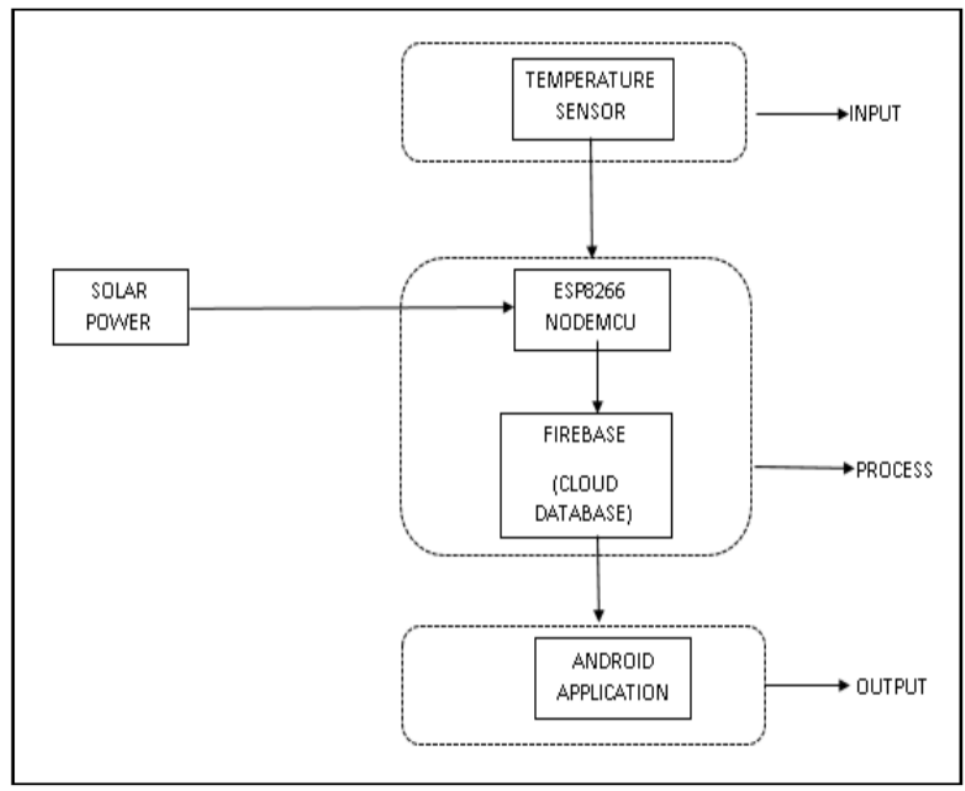

Figure 4. Application tier

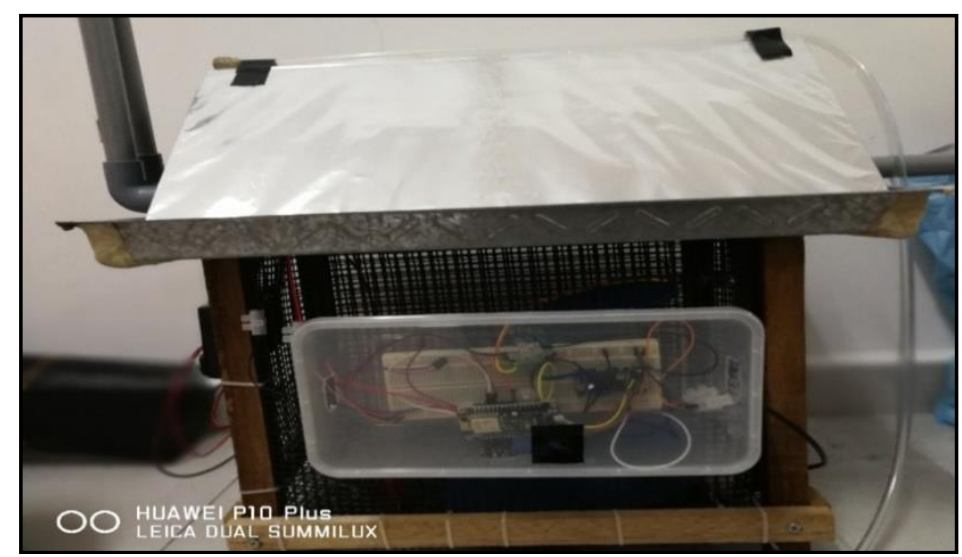

Figure 5. The REMACT prototype

\section{RESULTS AND ANALYSIS}

Analysis are implemented for the system development. Implementation phase is one of the important aspects that is necessary in developed system or application to meet the specified specifications. The entire system or application requirement that implemented gradually in this phase. The testing phase is necessary to ensure the system or application is free from any error and achieved the desired quality. In testing phase, all the problems and errors need to solve. The result to the test are very important to demonstrate the true capabilities of the system or application. For the implementation or development of the system, the code section of the procedure for a particular process also will explained in this chapter.

In order to achieve the objective of a system development, the system testing process is important. Testing case as Table 1 and Table 2 are done on the system to ensure that the system work as intended. The functional testing process need to be done so that the system produces the desired output and no error can affect the system process. 


\begin{tabular}{lc}
\multicolumn{2}{c}{ Table 1. REMACT Prototype Testing } \\
\hline \multicolumn{1}{c}{ Testing Case } & Result \\
\hline REMACT prototype can detect temperature & Successful \\
REMACT prototype success to make sure water pump or lamp either switch on or & Successful \\
off after detect the temperature. & Successful \\
REMACT prototype succeeded in connecting to the network/Internet & Successful \\
\hline
\end{tabular}

Table 2. REMACT Application Testing

\begin{tabular}{ll}
\hline \multicolumn{1}{c}{ Testing Case } & Result \\
\hline REMACT application can take data from Firebase & Successful \\
REMACT application can issued a notification after REMACT prototype detect the & Successful \\
temperature & \\
REMACT application can display the temperature value in the graph form. & Successful \\
\hline
\end{tabular}

The following figures show temperature changes when REMACT prototype is activated. Figure 6 shows the result when the extreme temperature occured and REMACT system controlled it back to normal temperature. The result shows the temperature drops during hot day from $33^{\circ} \mathrm{C}$ to $27^{\circ} \mathrm{C}$ with duration three and half hours after REMACT system is activated (water pump is on).

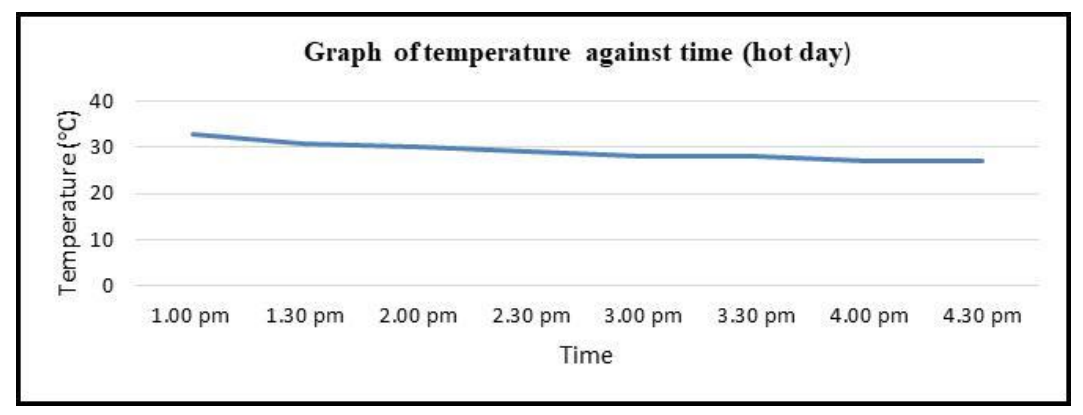

Figure 6. REMACT system activated (high temperature to normal temperature)

Figure 7 shows the graph when raining day occur. REMACT system will be activated and controlled low temperature to normal temperature. Both function is benefit to reduce the number of chicken died. The result shows the temperature drops during cold day from $25^{\circ} \mathrm{C}$ to $20^{\circ} \mathrm{C}$ and back to healthy range temperature $24^{\circ} \mathrm{C}$ with duration four and half hours after REMACT system is activated (lamp is on).

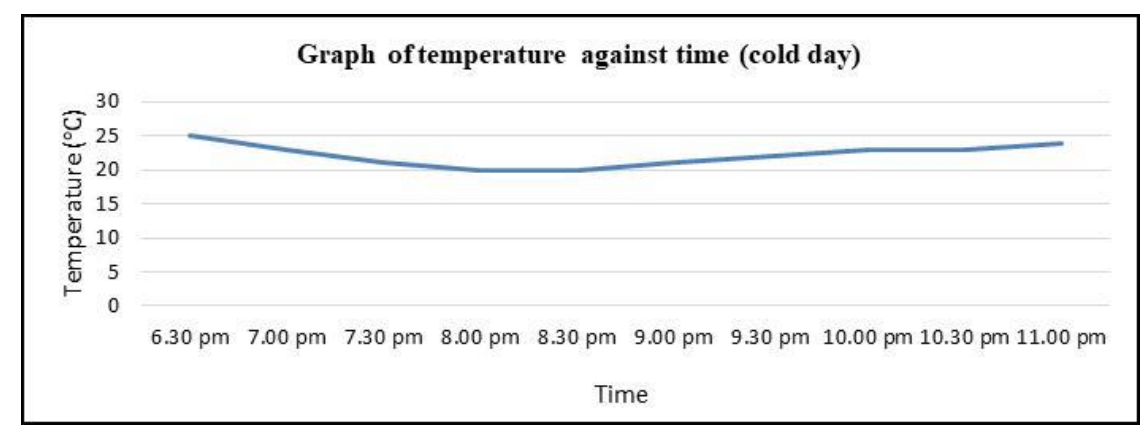

Figure 7. Graph of REMACT system activated (Low temperature to normal temperature)

\subsection{User Testing Findings on Application Features Evaluation}

Figure 8 below shows the results from respondents for application features in REMACT application. Most of the respondents satisfy the features because contains useful information and notification system will make chicken breeder be more alert to their chicken coop temperature. 


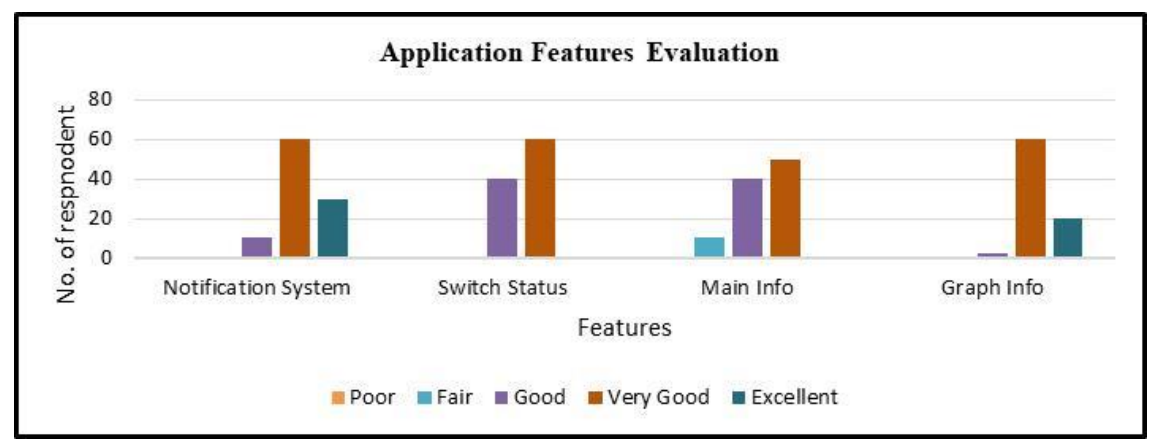

Figure 8. Findings on application features evaluation

\subsection{User Testing Findings on REMACT Performance}

Figure 9 shows the results from respondent toward performance on REMACT application and its prototype. Most of the respondent give the positive feedbacks were both of performance are good and two respondent give few negative feedbacks such as facing on lag problem that need to force close during monitoring the chicken coop temperature.

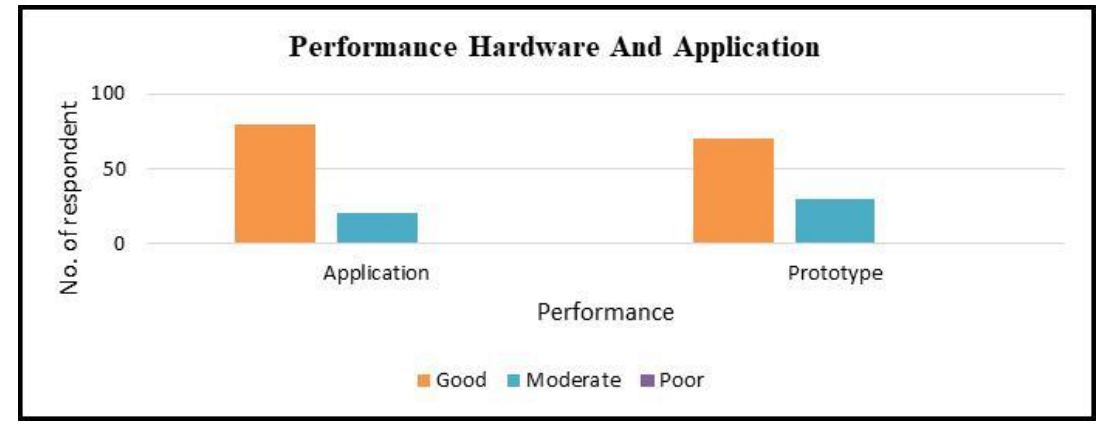

Figure 9. Findings on performance of REMACT hardware and software

\section{CONCLUSION}

A healthy coop temperature range is necessary to ensure good poultry production. REMACT coop cooling system has been designed with IOT technologies, sensors, solar panels and a water roof irrigation system. Sufficient intelligence is added to provide autonomous feature and also a mobile application to monitor temperature in real time. The smartphone application receives notification of current temperatures inside the chicken coop. As required, water will irrigate the roof if the temperature is high or heat lamp will be activated if the temperature is low.

For future work, optimum coop humidity can also be controlled by extending the existing REMACT system. Adding other sensors like flood and fire detector may add more safety to the whole coop ecosystem. To optimise energy usage, fans system can be added with auto shut off and controlled from the IOT controller.

\section{ACKNOWLEDGEMENT}

This study is supported by a research grant under Ministry of Higher Education, Malaysia, Fundamental Research Grant Scheme Vot 1609 and partly sponsored by Gates IT Solution Sdn. Bhd.

\section{REFERENCES}

[1] Osti R, Bhattarai D, Zhou D. Climatic Variation: Effects on Stress Levels, Feed Intake and Bodyweight of Broilers. Brazilian Journal of Poultry Science. 2017; 19(3): 489-496.

[2] Damerow G. The Chicken Health Handbook: A Complete Guide to Maximizing Flock Health and Dealing with Disease. Second Edition. Massachusetts: Storey Publishing, LLC. 2015. 
[3] Mendes AS, Sandro PJ, Restelatto E, Morello GM, Moura DJ, Carlo PJ. Performance and Preference of Broiler Chickens Exposed to Different Lighting Sources.The Journal of Applied Poultry Research. 2013; 12(1): 62-70.

[4] Dhia AA. Cooling Poultry Basic Principles of Humidity and Temperature Control. Journal of Cooling Poultry Houses. 2012; 12(1): 1-21.

[5] Phil G, Robert P. Poultry housing a management in developing countries. Poultry Development Review. Food and Agriculture Organization of the United Nations (FAO). 2013: 24-28.

[6] Ahachad M, Belarbi R, Bouaziz N, Draoui A, Allard F. Poultry housing in the Arab World. Applying principles of thermal exchange to improve performance (A case study of Morocco). 2008:60-75.

[7] Ray PP. A survey on Internet of Things architectures. Journal of King Saud University - Computer and Information Sciences. 2016; 30(3): 291-319.

[8] Choi H, Song J, Yi K. Brightics-IoT: Towards Effective Industrial IoT Platforms for Connected Smart Factories. In the Proceedings of the IEEE International Conference on Industrial Internet (ICII). Seattle, WA. 2018: 146-152.

[9] Elijah O, Rahman TA, Orikumhi I, Leow CY, Hindia MN. An Overview of Internet of Things (IoT) and Data Analytics in Agriculture: Benefits and Challenges. IEEE Internet of Things Journal. 2018; 5(5): 3758-3773.

[10] Zhang H, Li J, Wen B, Xun Y, Liu J. Connecting Intelligent Things in Smart Hospitals Using NB-IoT. IEEE Internet of Things Journal. 2018; 5(3): 1550-1560.

[11] Shyam GK, Manvi SS, Bharti P. Smart waste management using Internet-of-Things (IoT). In the Proceedings of the 2nd International Conference on Computing and Communications Technologies (ICCCT). Chennai. 2017: 199-203.

[12] UpSkill Learning. ESP8266: Get Started with ESP8266 Programming NodeMCU Using Arduino IDE. First Edition. CreateSpace Independent Publishing Platform. 2016.

[13] Sipani JP, Patel RH, Upadhyaya T. Temperature and Humidity Monitoring \& Control System Based on Arduino and SIM900A GSM Shield. International Journal of Electrical, Electronics and Data Communication. 2017; 5(11): 62-68.

[14] Osaretin CA, Edeko FO. Design and Implementation of Solar Charge Controller with Variable Output. Journal of Electrical and Electronics Engineering. 2016; 12(2): 40-52.

[15] Kamar I, Hamie A, Parag C. Internet of Things in Learning Systems - A Perspective of Platforms. International Journal of Advanced Research in Computer Science. 2016; 7(2): 52-56. 